\title{
EFEKTIVITAS VAGAL NERVE STIMULATION (VNS) TERHADAP DISRITMIA JANTUNG
}

\author{
Pius A. L. Berek *) \\ *) Nursing Program at University of Timor, Jl. Wehor Kabuna Haliwen, Atambua, East Nusa \\ Tenggara, Indonesia. E-mail: francis_domin2012@yahoo.com Phone number: +6281280426042
}

\begin{abstract}
ABSTRACK
Dysrhythmia is a heart rate disorder that includes frequency or rhythm disorders or both. One of the nursing actions to overcome is doing Vagal Nerve Stimulation (VNS), includes emphasis on one side of carotid sinus, emphasis on periorbital sinus, and performing valsalava maneuver by coughing. This is believed to increase release of acetylcholine in heart, where the acetylcholine is captured by SA node in left atrium and serves as an inhibitor of electrical stimulation of heart. The release of acetylcholine production is expected to inhibit cardiac irritability so ventricular contraction can be reduced to a minimum. This will appear clearly in state of dysrhythmias, especially atrial fibrillation. In atrial fibrillation, the impulses produced in atrium will exceed normal state, which results in electrical conductance of heart to SA node, continued to AV node and to purkinje fibers to increase ventricular contractions in projecting blood out of heart. If the impulses produced by atrium are irregular, the same thing happens to ventricles, which is to make irregular heart contractions as well. The result is the heart does not have time to relax to give blood to coronary arteries. If not handled properly, this is very dangerous for heart. VNS action by providing stimulation to vagus nerve will greatly help overcome this problem because the ends of the vagus nerve lead to SA node and AV node. By providing stimulation to vagus nerve, the signal will be sent to efferent to release ACh. It is hoped that this ACh will inhibit impulses from SA node and AV node so the heart can contract according to the body's needs.
\end{abstract}

Key Words: Dysrhythmia, Vagal Nerve Stimulation

\begin{abstract}
ABSTRAK
Disritmia adalah suatu kelainan denyut jantung yang meliputi gangguan frekuensi atau irama atau keduanya. Salah satu tindakan keperawatan untuk mengatasinya adalah melakukan Vagal Nerve Stimulation (VNS), yang meliputi penekanan pada salah satu sisi sinus karotis, penekanan pada sinus periorbital, serta melakukan valsava maneuver dengan cara batuk. Ini diyakini dapat meningkatkan pengeluaran asetilkolin pada jantung, dimana asetilkolin ini ditangkap oleh SA node di atrium kiri dan berfungsi sebagai penghambat rangsangan listrik jantung. Keluarnya produksi asetilkolin ini diharapkan dapat menghambat iritabilitas jantung sehingga kontraksi ventrikel dapat ditekan seminimal mungkin. Hal ini akan nampak jelas pada keadaan disritmia khususnya atrial fibrilasi. Pada atrial fibrilasi, impuls yang dihasilkan di atrium akan melebihi keadaan normal, yang mengakibatkan hantaran listrik jantung ke SA node, dilanjutkan ke AV node serta ke serabut purkinje untuk meningkatkan kontraksi ventrikel dalam mengejeksikan darah keluar dari jantung. Apabila impuls yang dihasilkan oleh atrium tidak beraturan, hal yang sama juga terjadi pada ventrikel yaitu melakukan kontraksi jantung secara tidak beraturan pula. Akibatnya adalah jantung tidak sempat relaksasi untuk memberikan darahnya kepada arteri-arteri koroner. Jika tidak ditangani dengan baik, hal ini sangat berbahaya bagi jantung. Tindakan VNS dengan cara memberikan rangsangan pada nervus vagus akan sangat membantu mengatasi permasalahan ini karena ujung-ujung saraf vagus bermuara pada SA node dan AV node. Dengan memberikan rangsangan pada nervus vagus tersebut, maka signal akan dikirim ke efferen untuk mengeluarkan ACh. Diharapkan ACh ini akan menghambat impuls yang dari SA node dan AV node sehingga jantung dapat berkontraksi sesuai dengan kebutuhan tubuh.
\end{abstract}

Kata Kunci: disritmia, vagal nervous stimulation 


\section{PENDAHULUAN}

Jantung dipersarafi oleh serabut simpatis dan parasimpatis susunan saraf otonom melalui plexus cardiacus yang terletak di bawah arkus aorta. Saraf simpatis berasal dari bagian cervicale dan thoracale bagian atas truncus sympathycus, dan persarafan parasimpatis berasal dari nervus vagus. Serabut-serabut postganglionik simpatis berakhir di nodus sinusatrial dan nodus atrioventrikular, serabutserabut otot jantung dan arteria koronaria. Perangsangan saraf simpatis mengakibatkan akselerasi jantung, meningkatkan denyut jantung (daya kontraksi otot jantung) dan dilatasi arteria koroner. Sedangkan perangsangan saraf parasimpatis mengakibatkan berkurangnya denyut jantung (daya kontraksi otot jantung) dan konstriksi arteria koroner. Serabutserabut aferen yang berjalan bersama nervus vagus mengambil bagian dalam refleks kardiovaskular (Tortora \& Derickson, 2007).

Infark miokard akut (IMA) adalah suatu keadaan di mana terjadi nekrosis otot jantung akibat ketidakseimbangan antara kebutuhan dengan suplai oksigen yang terjadi secara mendadak (Brunner - Suddarth, 2002).

IMA yang sering dikenal sebagai serangan jantung ini merupakan suatu serangan yang terjadi secara tiba - tiba dan sulit diduga hasil akhirnya. Umumnya kematian yang terjadi akibat serangan jantung ini sangat cepat hanya dalam hitungan menit. Serangan jantung yang biasa dikenal dengan Infark Miokard ini terjadi sebagai akibat dari proses rusaknya jaringan miokardium (otot miokardium) akibat suplay darah yang tidak adekuat sehingga aliran darah koroner menjadi berkurang. Penyebab penurunan suplai darah ini mungkin akibat dari penyempitan kritis dari arteri koroner karena aterosklerosis atau penyumbatan total oleh emboli atau thrombus. Juga karena syok atau perdarahan. Hal hal tersebut akan menyebabkan ketidakseimbangan antara suplai dan kebutuhan akan oksigen jantung. Satu hal yang terjadi pada jantung sendiri bahwa ketika jantung mengalami ketidakseimbangan antara suplai dan kebutuhan oksigen, secara otomatis jantung akan melakukan kompensasi dengan cara mempercepat frekuensi jantung yang pada akhirnya akan meningkatkan kontraksi jantung. Kontraksi jantung (ventrikel) akan menghasilkan sebaran atau ejeksi sejumlah darah untuk memenuhi kebutuhan tubuh. Namun apabila terjadi suatu ketidakseimbangan pada salah satu sifat dasar jantung, maka terjadilah irama dan frekuensi jantung yang tidak diharapkan yang dikenal sebagai disritmia.

Disritmia adalah suatu kelainan denyut jantung yang meliputi gangguan frekuensi atau irama atau keduanya (Brunner - Suddarth, 2002). Ketidakseimbangan pada salah satu sifat dasar otot jantung dapat disebabkan oleh aktivitas normal seperti pada saat latihan, namun lebih banyak sering terjadi karena keadaan patologis seperti infark miokard. Pada infark miokard, terjadi peningkatan 
Tersedia Online di: https://jurnal.unimor.ac.id/JSK

respons miokardium terhadap stimulus akibat penurunan oksigenasi ke miokardium yang menyebabkan terjadinya peningkatan eksitabilitas. Kelainan irama dan atau frekuensi pada kondisi disritmia ini dapat terjadi dimana saja pada bagian jatung, baik pada nodus atria, nodus AV maupun di ventrikel. Berbagai lokasi ini akan memberi nama untuk tiap jenis disritmia. Hal buruk yang terjadi dari disritmia ini adalah frekuensi jantung yang sangat cepat sehingga jantung sulit memberikan darah kepada arteri koronernya sendiri. Kondisi kurangnya suplai darah ke arteri koroner ini akan berdampak bagi individu dimana akan mengalami serangan jantung. Apabila terlambat ditangani, maka kematian akan segera terjadi. Adapun jenis disritmia yang terjadi dan menghasilkan frekuensi jantung yang cepat tersebut antara lain atrial flutter dengan frekuensi 250 - 400 kali/menit. Atrium flutter terjadi bila ada titik focus di atrium yang menangkap irama jantung dan membuat impuls menjadi cepat. Frekuensi yang sangat cepat ini akan menyebabkan penurunan pengisian arteri koroner yang akan menurunkan curah jantung. Hal ini terjadi karena impuls yang sangat banyak dari atrium menyebabkan hantaran rangsangan ke ventrikel sehingga ventrikel berespons begitu cepat. Akibat dari kondisi ini akhirnya mengurangi pengisian ventrikel. Pada saat yang sama volume sekuncup juga mengalami gangguan. Agar kondisi ini tidak berkelanjutan dan kualitas hidup pasien dapat dipertahankan, maka perlu adanya suatu penanganan professional agar kematian akibat masalah jantung ini dapat ditekan hingga titik serendah-rendahnya.

VNS terapi merupakan sebuah istilah yang digunakan untuk menggambarkan atau menjelaskan teknik untuk melakukan rangsangan pada nervus vagus. Bermula dari suatu pemandangan menarik sejak tahun 1880 dimana adanya massage dan penekanana manual pada arteri carotis leher dapat menekan serangan seizure sebagai efek dari rangsangan pada nervus vagus. Dilanjutkan dengan penelitian sepanjang tahun 1930 - 1940 dan didapatkan hasil bahwa VNS ini akan mempengaruhi aktivitas listrik otak dan memberikan kenyamanan bagi pasien tersebut. Hal yang sama juga diberikan kepada pasien depresi, dan ternyata memberikan hasil yang menggembirakan. Dengan berlalunya waktu, studi menarik telah dilakukan pula untuk mengatasi berbagai masalah kesehatan lainnya diantaranya adalah masalah atrial fibrilasi. Salah satu jenis manipulasi atau stimulasi untuk meningkatkan kerja persarafan parasimpatis ini adalah melakukan Slow Deep Breathing (Berek, 2010). Slow Deep Breathing (SDB) ini telah dilakukan untuk menurunkan tekanan darah baik sistolik maupun diastolik, dan belum dilakukan penelitian untuk mengatasi masalah disritmia jantung ini.

Berdasarkan fenomena diatas, maka penulis tertarik untuk melihat lebih jauh tentang efektifitas stimulasi nervus vagus pada pasien disritmia. Semua tindakan ini adalah merupakan sebuah strategi terbaik untuk mencari 
Tersedia Online di: https://jurnal.unimor.ac.id/JSK

dasar intervensi yang rasional dalam mengembangkan ilmu keperawatan masa mendatang.

\section{ANATOMI SARAF PARASIMPATIS DAN JANTUNG}

Bodi sel dari saraf preganglionik terletak didalam nuclei vagal (dorsal motor neuron pada vagus dan ambiguus nuclei). Axon dari neuron ini terbagi menjadi dua bagian: bilateral vagus nervus yang melewati ujung arteri carotis dan sinaps neuron postganglionik yang terletak pada permukaan jantung yang sangat dekat pada SA node dan AV node.

Walau terjadi overlap, vagus kanan inervasi terbesar pada jantung dan bersentuhan langsung dengan SA node, sedangkan vagus kiri berpengaruh besar pada AV node. Sehingga rangsangan elektrik pada vagus kanan akan menurunkan otomatisasi dari SA node (memperlambat kerja jantung, bahkan terjadi henti jantung), sedangkan rangsangan pada vagus kiri akan menghasilkan AV blok yang bervariasi.

\section{MEKANISME KERJA SARAF PARASIMPATIS}

Potensial aksi pada
postganglionik saraf parasimpatis akan menyebabkan pelepasan neurotransmiter (Acetylcholin $=A C h$ ). ACh akan berikatan dengan reseptor Muscarinic cholinergic dan secara cepat akan membuka saluran ion ligand-gated, menyebabkan konduktansi $\mathrm{K}+$ menjadi meningkatkan didalam sel pacemaker. Akibatnya akan segera terjadi hiperpolarisasi potensial membran serta menurunkan kecepatan fase ke-4 depolarisasi dan automatisasi pacemaker. Dengan demikian terjadilah perlambatan kontraksi jantung. Rangsangan parasimpatis jantung tidak mempunyai efek yang signifikan pada kontraksi ventrikel. Reseptor muscarinic dirangsang oleh agonist parasimpatis: muscarine dan dapat diblok atau dihambat oleh antagonist muscarinic: atropin. Aksi parasimpatis pada otot kardiak secara cepat dapat dihentikan dengan degradasi enzimatic acetylcholine (acetylcholinesterase). Konsentrasi cholinesterase yang tinggi pada SA node dan AV node akan menyebabkan vagal inhibisi pada heart rate dengan sangat cepat (50 $100 \mathrm{msec}$ ). Karena aksi parasimpatis ini sangat cepat, maka aksi parasimpatis ini dapat digunakan untuk menurunkan heart rate.

Sistem saraf parasimpatis berinervasi secara efektif hanya pada beberapa area jantung, yaitu SA node, AV node dan saluran konduksi atrial. Sistem saraf parasimpatis ini kurang berpengaruh pada serabut-serabut kontraktil jantung. Rangsangan yang kuat pada psistem saraf parasimpatis jantung akan menyebabkan kontraksi jantung yang sangat lambat bahkan bisa menyebabkan henti jantung. Hal ini disebabkan karena konduksi yang melewati jantung telah dihambat dan menjadi sangat lambat terutama pada AV node.

\section{PATOFISIOLOGI NERVUS VAGUS}

Serabut preganglionik parasimpatis sistem saraf berjalan hampir ke semua organ yang dipersarafi, dan sinap pada ganglia 
Tersedia Online di: https://jurnal.unimor.ac.id/JSK

yang dekat atau berada pada organ tersebut, meningkatkan impuls ke serabut postganglionik yang mempersarafi jaringan yang sesuai. Sel ganglion dapat terorgansisir menjadi satu (mis. Pleksus mienterikus pada usus halus) atau dapat juga difus (mis. Vesica urinaria, pembuluh darah). Serabut preganglionik terbanyak pada nervus vagus. Nervus vagus $(X)$ membawa serabut saraf ke jantung. Secara fisiologis, sistem parasimpatis lebih digunakan pada penyimpanan dan pemulihan energi, oleh karena itu, maka akan mengurangi frekuensi detak jantung dan tekanan darah, menghambat lancarnya penghantaran impuls melalui jaras atrioventikular, memfasilitasi digestif dan absorpsi nutrien, maka dari itu akan mengekskresikan produk buangan, menyempitkan diameter pupil, melebarkan pembuluh darah, menyempitkan lumen bronkioli, menggalakkan sekresi air liur dan air mata, menggalakkan peristaltik dan melonggarkan sfinkter saluran pencernaan, menggalakkan otot detrusor kandung kemih, dan sekresi insulin, sehingga menurunkan gula darah. Transmiter kimia pada sinapsis pre dan postganglionik pada sistem parasimpatik adalah Asetilkolin (Ach). Serabut saraf yang mengeluarkan asetilkolin dari end plate (ujung)-nya disebut sebagai serabut kolinergik. Sintesis Ach terjadi di sitoplasma ujung neuron kemudian disimpan di vesikel terminal presinaptik. Adanya aksi presinaptik menyebabkan influks ion kalsium dan menyebabkan pelepasan beberapa ratus vesikel ke celah sinaptik. Ach kemudian diikat oleh reseptor spesifik pada membran postsinaptik dan meningkatkan permeabilitas membran terhadap ion sodium, potasium, dan kalsium, yang kemudian akan eksitasi postsinaptik. Aksi dari Ach ini berakhir oleh enzim Acetyl Cholinesterase yang akan segera menghidrolisisnya.

Reseptor Ach spesifik telah dibagi secra farmakologis berdasarkan aksi terhadap alkaloid muskarinik dan nikotin. Aksi Ach pada sinaps preganglionik baik sistem parasimpatik maupun simpatik diperankan oleh nikotin, dan semua ganglion autonomik juga disebut nikotinik. Aksi Ach pada ujung saraf postganglionik parasimpatis diperankan oleh muskarinik.

\section{EFEKTIFITAS VNS PADA PASIEN DISRITMIA (ATRIAL FIBRILASI)}

Otot jantung memiliki beberapa sifat asli, antara lain 1) otomatisasi adalah: memungkinkan sel mencapai potensial ambang dan membangkitkan impuls tanpa adanya stimulus dari sumber lain; 2) eksitabilitas, yaitu kemampuan sel miokardium untuk merespon stimulus; 3) konduktivitas, mengacu pada kemampuan otot jantung untuk menghantarkan impuls dari satu sel ke sel lain; dan 4) konyraktilitas, memungkinkan otot untuk untuk memendek pada saat terjadi stimulasi. (Brunner - Suddarth, 2002). Sifat-sifat ini akan membantu jantung melakukan adaptasi dalam mencapai keseimbangan / ekuilibrium. Semua kejadian alamiah tersebut terjadi dalam keadaan tidak disadari. Apabila semua sifat otot jantung tersebut bekerja dalam rangkaian yang utuh, maka otot jantung akan 
Tersedia Online di: https://jurnal.unimor.ac.id/JSK

distimulasi oleh impuls yang berasal dari nodus sinus, dalam hal ini nodus sinus dianggap sebagai pemacu jantung. Selanjutnya impuls akan diteruskan ke AV node dan melalui bundle branch impuls akan diteruskan ke serabut-serabut purkinje dan akhirnya terjadilah kontraksi miokard untuk mengejeksikan sejumlah darah. Selama rangsangan berasal dari nodus sinus yang berada didalam atrium jantung masih bekerja dengan baik, maka jalur hantaran normal linstrik jantung akan terjadi dengan baik yang pada akhirnya akan terjadi kontraksi ventrikel yang normal. Apabila sifat-sifat otot jantung tersebut terganggu, maka akan terjadilah disritmia.

Disritmia adalah suatu kelainan denyut jantung yang meliputi gangguan frekuensi atau irama atau keduanya (Brunner - Suddarth, 2002). Penanganan kasus ini lebih difokuskan pada bagaimana mengurangi iritabilitas atrium dan mengurangi frekuensi ventrikel. Secara cepat perawat dapat melakukan tindakan kolaborasi untuk memberikan terapi medikamentosa jenis preparat digitalis dan quinidin untuk memperlambat frekuensi jantung dan menekan disritmia tersebut. Selain itu untuk mencegah terjadinya tromboemboli yang dapat terbentuk di atrium akibat turbulensi darah, maka kolaborasi terapi antikoagulan dapat diberikan (Brunner - Suddarth, 2002). Hal ini penting dilakukan karena umumnya tidak sedikit pasien yang mengalami disritmia (atrial fibrilasi), akan mengalami strok karena terjadi emboli dan trombus yang berasal dari turbulensi pada atrium tersebut (Astiawati, T \& Baktijasa, B, 2009). Namun lebih lanjut Howland (2001) mengatakan bahwa farmakotherapi tidak efektif untuk semua pasien untuk itu maka terapi alternative sangat dibutuhkan. Hal ini memiliki tujuan yang sama yaitu untuk memperlambat frekuensi jantung dan menekan disritmia yang terjadi. Salah satu jenis terapi alternative (non farmakologis) yang dapat dilakukan adalah stimulasi nervus vavus (Vagus Nerve Stimulation = VNS). VNS merupakan suatu jenis tindakan dengan melakukan rangsangan atau stimulus pada nervus vagus yang bertujuan untuk meningkatkan kerja dari system saraf parasimpatis dan akhirnya memperlambat atau menghentikan serangan disritmia. Tindakan dalam VNS ini meliputi penekanan pada salah satu sisi sinus karotis, penekanan pada sinus periorbital, serta melakukan valsava maneuver. Tindakan - tindakan ini diyakini dapat meningkatkan pengeluaran asetilkolin pada jantung. Umumnya asetilkolin ini ditangkap oleh SA node di atrium kiri dan berfungsi sebagai penghambat rangsangan listrik jantung. Keluarnya produksi asetilkolin ini diharapkan dapat menghambat iritabilitas jantung sehingga kontraksi ventrikel dapat ditekan seminimal mungkin. Hal ini akan nampak jelas pada keadaan disritmia khususnya atrial fibrilasi. Pada atrial fibrilasi, impuls yang dihasilkan di atrium akan melebihi keadaan normal, yang mengakibatkan hantaran listrik jantung ke SA node, dilanjutkan ke AV node serta ke serabut purkinje untuk meningkatkan kontraksi ventrikel dalam 
Tersedia Online di: https://jurnal.unimor.ac.id/JSK

mengejeksikan darah keluar dari jantung. Apabila impuls yang dihasilkan oleh atrium tidak beraturan, hal yang sama juga terjadi pada ventrikel yaitu melakukan kontraksi jantung secara tidak beraturan pula. Akibatnya adalah jantung tidak sempat relaksasi untuk memberikan darahnya kepada arteri-arteri koroner. Jika tidak ditangani dengan baik, hal ini sangat berbahaya bagi jantung. Tindakan VNS dengan cara memberikan rangsangan pada nervus vagus akan sangat membantu mengatasi permasalahan ini karena ujung-ujung saraf vagus bermuara pada SA node dan AV node. Dengan memberikan rangsangan pada nervus vagus tersebut, maka signal akan dikirim ke efferen untuk mengeluarkan ACh (Lewis, M.E., at all, 2001). Diharapkan ACh ini akan menghambat impuls yang dari SA node dan AV node sehingga jantung dapat berkontraksi sesuai dengan kebutuhan tubuh. Lewis, M.E., at all (2001) dalam penelitiannya menemukan bahwa dengan adanya rangsangan pada nervus vagus secara elektrik, jantung akan berespon dengan cepat untuk menurunkan status inotropik pada miokardium ventrikel kiri tanpa adanya efek bradikardia. Hayashi, I., at all (2001) menemukan bahwa pada binatang percobaan yang dilakukan tindakan CABG tanpa CPB (Cardiopulmonary Bypass), dan dilakukan stimulasi nervus vagus pada cervical kanan dapat menurunkan heart rate rata-rata 190 menjadi 45 kali/menit. Masih dalam penelitian yang sama, hewan coba yang diberikan infus diltiazem (10-20 $\mathrm{mg} / \mathrm{jam})$ stimulasi vagal menyebabkan ventrikular arrest. Hewan coba yang diberikan infus verapamil (5 mg/jam), stimulasi vagal dapat menyebabkan bradikardia dengan AV block. Sedangkan pada hewan coba mendapat right thoracotomy untuk isolasi dan stimulasi right thoracic vagal nerve, terjadi penurunan heart rate dari 205 menjadi 70 kali/menit. Selain itu thoracic vagal stimulation selama pemberian intravena diltiazem, terjadi bradikardi dengan AV block. Setelah pelaksanaan rangsangan nervus vagus, jantung kembali menjadi irama sinus normal dengan sangat cepat. Pada postoperatif, hewan coba mengikuti fase-fase pemulihan tanpa adanya kesulitan yang berarti. Semua kejadian diatas dilakukan dengan menggunakan tindakan operatif dan ventilasi mekanik. Selain itu menurut Shelchuk \& Anne (2007) dikatakan bahwa cardiac output dapat dipertahankan atau ditingkatkan dengan cara mempertahankan keseimbangan saraf autonomik melalui rangsangan pada satu atau lebih saraf parasimpatis (vagus). Metode ini meliputi pengiriman satu atau lebih stimulasi pulsasi pada postinspirasi dan atau berdasarkan pada pendeteksian satu atau lebih kerja jantung.

Berek et al, (2015) dalam penelitiannya menemukan bahwa nervus vagus ini juga dapat dimanipulasi melalui tindakan Slow Deep Breathing, namun demikian penelitiannya yang dilakukan tersebut belum menyentuh ke area disritmia jantung. 
Tersedia Online di: https://jurnal.unimor.ac.id/JSK

\section{APLIKASI DI KLINIK TENTANG PENANGANAN DISRITMIA DAN KESENJANGAN ANTARA TEORI DAN PRAKTIK.}

Aplikasi VNS Therapy ini sudah banyak dilakukan pada pasien yang mengalami gangguan jiwa terutama pada kasus epilepsi (sejak 1970) dan depresi (sejak 1993). Therapi VNS untuk masalah kejiwaan ini sudah mendapat persetujuan dan direkomendasikan oleh FDA dan AHA untuk digunakan pada kedua jenis penyakit tersebut. Sedangkan untuk kasus lainnya seperti jantung, sedang dikembangkan berbagai penelitian terkait. Penelitian terakhir ditemukan bahwa experimen yang dilakukan pada hewan coba, jika dilakukan stimulasi pada salah satu sisi nervus vagus akan memberikan hasil yang signifikan, namun apabila stimulasi yang diberikan tersebut melebih frekuensi yang ada, malah akan meninbulkan masalah lain yang tidak diharapkan seperti Bradikardia, AV blok bahkan sampai henti jantung (Howland, R. H., 2006). Walau demikian, namun penelitian terkait VNS ini masih menarik untuk dilakukan lebih lanjut karena telah diyakini bahwa secara anatomi dan fisiologi, nervus vagus dapat menghasilkan Ach yang berperan menurunkan kontraksi jantung. Hal ini sangat bermanfaat bagi pasien atrial fibrilasi.

\section{PERAN PERAWAT SPESIALIS DALAM APLIKASI DI KLINIK TERKAIT VNS}

Perawat spesialis adalah
seorang perawat yang telah
memperoleh pendidikan dan lulus dari

program Master atau Doktor. Perawat spesialis klinik merupakan perawat yang memiliki keahlian dalam menegakan diagnosis dan merawat pasien dengan berbagai gangguan penyakit dengan menggunakan intervensi keperawatanberdasarkan EBN (ANA, 2004). Terdapat tiga area yang menjadi lahan praktek perawat spesialis klinik, yaitu : pasien/keluarga, staf perawatan dan system/jaringan organisasi.

Sparacinio (2005) telah mengidentifikasi Tujuh kompetensi utama yang harus di miliki seorang perawat spesialis yaitu :

1. Praktik Klinik Langsung: Perawat spesialis mempunyai peran yang sangat besar untuk melakukan asuhan keperawatan mulai dari pengkajian sampai dengan evaluasi. Hal penting yang perlu dilakukan perawat spesialis dalam melakukan pengkajian ini adalah kemampuan untuk menentukan bahwa disritmia yang ada adalah berasal dari atrium atau dari ventrikel. Suatu hal penting yang menuntut kejelian dari perawat spesialis. Upaya yang harus dilakukan yaitu perawat perlu memahami tentang komponenkomponen jantung dan aktivitas aktivitasnya dalam melakukan pompa jantung untuk mengeluarkan darah dalam memenuhi kebutuhan tubuh. Aktivitas atau kontraksi jantung tersebut yaitu bahwa impuls berasal dari SA node melalui bundle branch akan diteruskan ke AV node, selanjutnya impuls akan terpisah melalui berkas of his baik 
Tersedia Online di: https://jurnal.unimor.ac.id/JSK

kir dan kanan untuk mencapai ventrikel dan dengan kekuatan yang ada, akan terjadilah kontraksi jantung untuk mengirimkan sejumlah darah untuk mencukupi kebutuhan tubuh. Perlu diketahui juga oleh perawat spesialis bahwa secara fisiologis, jantung bekerja secara tak sadar, dan dipengaruhi oleh sistem saraf otonom (simpatis). Semakin tingi aktivitas saraf simpatis, semakin tinggi pula kerja jantung dalam berkontraksi. Hal yang terjadi pada atrial fibrilasi, semakin tinggi rangsangan dari sistem saraf simpatis, akan menyebabkan jantung semakin cepat berkontraksi hingga mencapai > $300 \mathrm{x} /$ menit. Berbagai efek negatif yang terjadi pada keadaan atrial fibrilasi ini antara lain arteri koroner sendiri tidak akan mendapatkan asupandarah, nutrisi, oksigen yang memadai karena jantung tidak sempat berelaksasi untuk memberikan darahnya kepada koroner. Perlu kita ketahui kembali bahwa asupan darah ke koroner terjadi pada saat jantung dalam keadaan relaksasi. Hal lain yang terjadi dari atrial fibrilasi ini adalah terjadi strok akibat dari emboli akibat dari turbulensi darah dalam atrium. Perawat spesialis yang telah mengetahui atrial fibrilasi ini, diharapkan memegang peranan dalam melakukan asuhan keperawatan. Langkah utama yang harus dilakukan oleh peraat spesialis ini adalah melakukan pengkajian. Hal penting yang harus dilakukan oleh perawat spesialis karena dengan melakukan pengkajian yang baik, akan ditemukan masalah keperawatan yang baik pula. Kemampuan melakjukan pengkajian ini masih sangat jauh dari keperawatan, oleh karena itu diharapkan perawat spesialis mampu melakukan pengkajian ini dengan baik. Setelah melakukan pengkajian ini, maka akan dilakukan penentuan masalah keperawatan untuk dilakukan intervensi keperawatan yang memadai. Dalam hal melakukan intervensi keperawatan ini, penting untuk menentukan intervensi yang rasional dan dapat dipertanggungjawabkan. Salah satu intervensi yang bisa dilakukan adalah melakukan VNS terapi. Walau masih menimbulkan banyak kontradiksi karena hasil dari VNS ini belum bisa diaplikasikan, namun secara manual dapat dilakukan beberapa alternatif tindakan berupa masage pada area-area nervus vagus seperti periorbital, dan masage manual pada salah satu sisi leher untuk mengaktifkan aktivitas nervus vagus.

2. Bimbingan yang profesional: yaitu menerapkan model perawatan lanjutan pada saat membantu perawat pelaksana menerapkan EBN dalam praktek keperawatan. Termasuk juga memfasilitasi pendidikan kesehatan serta memberikan latihan yang memadai kepada pasien dan keluarga. Dalam hal terapi VNS ini, walau peran bimbingan dari perawat spesialis kepada bawahannya balum bisa diaplikasikan dengan baik, namun setidaknya ada suatu 
informasi baru bagi para perawat bahwa sebenarnya jenis tindakan yang ditawarkan oleh Brunner \& Suddarth (2002) untuk melakukan masage pada salah satu sisi leher dapat dilakukan untuk pasien atrial fibrilasi di wahana kerja kita. Sambil menanti hasil penelitian spektakuler yang sedang dilakukan saat ini oleh para ahli.

3. Collaboration berfokus pada multidisciplin. Sebagaimana kita ketahui bahwa atrial fibrilasi merupakan suatu gangguan kontraksi jantung yang terjadi pada daerah atrium. Umumnya pada kondisi atrial fibrilasi ini, dinding atrium pula akan menghasilkan stimulus yang sangat banyak sehingga akan menghasilkan rangsangan ke ventrikel secara berlebihan. Walau tidak beraturan, namun semua rangsangan yang dihasilkan di SA node dan sekitar dinding atrium akan diteruskan ke AV node dan diteruskan ke berkas of his yang kemudian akan menyebabkan kontraksi jantung yang sangat cepat. Secara anatomis dan fisiologi diketahui pula bahwa vagus dapat mengeluarkan Ach untuk menurunkan kontraksi jantung. Salah satu muara nervus vagus ini terdapat pada SA node dan AV node. Ketika rangsangan diberikan pada salah satu area sistem saraf parasimpatis (pada kedua sisi leher dan periorbital), diyakini akan membantu mengatasi keadaan atrial fibrilasi ini. Oleh karena itu VNS terapi merupakan salah terapi pilihan terbaik. Namun masih sangat disayangkan karena VNS terapi ini masih merupakan suatu hal yang sangat langka. Dampak dari kelangkaan ini menjadi suatu kesempatan terbaik bagi perawat spesialis untuk mendiskusikannya dengan disiplin ilmu lainnya. Suatu kesempatan istimewa bagi perawat spesialis untuk menjalankan peran kolaborasi ini. Dengan berbagai literatur yang ada, perawat spesialis dapat melakukan diskusi lintas multidisiplin untuk melakukan penelitian terkait.

4. Consultasi meliputi melakukan review terhadap alternative pemecahan masalah dan mengimplementasikan perubahan perencanaan. Perawat spesialis harus mengembangkan ilmu dan pengetahuannya tentang berbagai jenis disritmia yang ada karena setiap disritmia memiliki sumber masalah yang berbeda, dan penatalaksanaan yang berbeda pula. Untuk zaman sekarang ini, DC Shock masih merupakan pilihan terbaik untuk mengatasi kasus ventrikel fibrilasi, ventrikel tatikardi, termasuk didalamnya adalah atrial fibrilasi. Namun dengan berkembangnya ilmu pengetahuan dan teknologi, saat ini telah ditemukan strategi baru bahwa khusus untuk atrial fibrilasi, intervensi yang paling tepat adalah diberikan VNS terapi karena diyakini bahwa dengan VNS terapi dapat merangsang atau menghasilkan banyak ACh yang akan membantu menurunkan kerja jantung. Namun sayangnya belum ada hasil penelitian yang 
bermakna. Sehingga VNS terapi ini masih belum direkomendasikan untuk digunakan. Masih dalam proses penelitian.

5. Riset meliputi: melakukan penelitian, mengintepretasikan dan menggunakan hasil riset, melakukan evaluasi dan memadukan riset dalam pelaksanaan praktek perawatan. Sebagaimana penjelasan diatas bahwa kelangkaan jenis intervensi yang baik ini akan mengantarkan perawat spesialis untuk mampu membuat penelitian. HAsil dari penelitian tersebut akan menambha jenis intervensi keperawatan yang rasional dan up to date serta berdasarkan EBN. Namun karena jenis tindakan ini merupakan tindakan yang sangat berbahaya, maka penelitian experiment yang ditawarkan adalah dilakukan secara join lintas multidisiplin. Untuk merealisasikan hal ini, maka perawat spesialis perlu menjalin hubungan yang baik dengan berbagai disiplin profesi, menambah wawasan dan pengetahuan tentang jenis penyakit terkait serta berbagai hal yang berhubungan dengan intervensi dan sejenisnya.

6. Pemimpin yang professional: bertanggung jawab dalam melakukan inovasi dan perubahan terhadap system perawatan pada klien.

7. Membuat keputusan etik: bertanggung jawab dalam bernegosiasi terhadap terjadinya dilemma moral, menentukan sumber pemecahan dan membantu pasien dalam mendapatkan akses pelayanan.

\section{KESIMPULAN}

1. Transmiter kimia pada sinapsis pre dan postganglionik pada sistem parasimpatik merupakan Asetilkolin (Ach). Dalam aksinya ACh ini akan berikatan dengan dengan Muscarinic Cholinergic dan berefek pada menurunnya kontraktilitas miokardium jantung.

2. VNS terapi merupakan istilah yang digunakan untuk menjelaskan suatu jenis teknik melakukan stimulasi pada nervus vagus. Rangsangan pada nervus vagus ini diyakini akan mengeluarkan ACh, dimana sesuai dengan patofisiologisnya bahwa ACh yang dihasilka tadi akan berikatan dengan Muscarinic Cholinergic dan ditangkap oleh SA node dan AV node selanjutkan akan menghambat kontraksi miokard jantung.

3. Dewasa ini penangan disritmia jenis Atrial Fibrilasi dirumah sakit masih secara umum menggunakan terapi yang sudah ada yaitu DC Shok. Namun dari hasil penelitian mutakhir ditemukan bahwa tidak semua jenis disritmia bisa ditolong dengan DC Shok. Disritmia jenis Ventrikel Takikardia dan Ventrikel Fibrilasi akan lebih baik ditangani dengan DC Shok sedangkan disritmia jenis Atrial Fibrilasi menjadi lebih baik bila ditangani dengan menggunakan VNS Therapy. Namun demikian, 
penelitian lebih lanjut masih perlu dilakukan karena ternyata VNS terapi ini bisa membawa efek negatif bagi pasien yaitu terjadi bradikardia, AV blok bahkan sampai henti jantung.

4. Peran perawat spesialis sangat dibutuhkan untuk bisa menilai kondisi pasien. Hasil penilaiannya ini akan menjadi dasar baginya untuk melakukan peran kolaborasi sebagaimana perawat adalah mitranya dokter. Dengan mengetahui berbagai jenis disritmia yang ada dan mendiskusikan penggunaan terapi yang tepat akan semakin menunjukkan kemampuan atau kompetensi perawat yang memadai.

\section{SARAN}

1. Bagi Pelayanan Keperawatan Hendaknya semua perawat dibidang pelayanan kesehatan keperawatan di rumah sakit selalu mengembangkan kerjasama yang baik dan meningkatkan pengetahuannya sehingga bisa mendapatkan hal baru bagi pengembangan kariernya.

2. Bagi Perkembangan IImu Keperawatan

Penting bagi ilmu keperawatan untuk mengembangkan diri melalui pendidikan sepanjang hayat, sebab hampir setiap hari ditemukan strategi atau terapi baru untuk mengobati pasien. Walau perawat bertindak hanya untuk memenuhi kebutuhan dasar pasien, namun berbagai alat dan teknologi mutakhir penting juga diketahui oleh perawat karena dalam sistem pelayanan kesehatan, perawat adalah mitra kerja dengan tim kesehatan lain. Artinya bahwa perawat perlu mengimbangi diri dengan berbagai pengetahuan agar dalam menjalankan kehidupan sehari-hari dalam perawatan oasien, tidak dianggap sebelah mata oleh profesi lain hanya karena tidak memahami dan atau mengikuti perkembangan teknologi mutakhir untuk merawat pasiennya.

\section{Bagi Penelitian Keperawatan}

Hendaknya perawat tertarik juga untuk melakukan penelitian lebih lanjut tentang topik terkait sebab hal ini sangat menarik dan bisa dilakukan dengan aman. Sebagaimana inspirasi awal ditemukannya VNS terapi ini yaitu pada tahun 1880 diamati pada perilaku pasien epilesi yang melakukan massage dan penekanan manual pada daerah arteri karotis di leher dan ternyata bisa menyembuhkan. Dengan berlalunya waktu dan melalui penelitian, ditemukan bahwa ternyata dengan melakukan massage dan penekanan manual pada area tersebut akan merangsang keluarnya ACh yang yang sangat bermamnfaat bagi tubuh dan kesehatan manusia. 


\section{KETERBATASAN DAN KELEBIHAN VNS}

Keuntungan dari penggunaan VNS therapy diantaranya adalah dapat meningkatkan kualitas hidup pasien, karena masalah Aitrial Fribilasi dapat ditekan seminimal mungkin. Sebagaimana diketahui bahwa pada saat terjadi atrial firbilasi, akan diikuti dengan turbulensi darah di atrium dan menghasilkan berbagai trombus dan emboli yang akan meningkatka insiden strok. Hal ini akan lebih cepat diatasi dengan berbagai terapi medikamentosa, namun terapi nonmedikamentosa akan memberikan dampak yang lebih baik. Salah satunya adalah VNS ini. Namun penggunaan terapi ini masih memberi dampak negatif yang besar dimana apabila stimulus dilakukan pada kedua area nervus vagus secara bersamaan, malah dapat menimbulkan bradikardia. Selain itu juga dapat menyebabkan AV blok bahkan sampai henti jantung. Untuk itu penelitian yang lebih lanjut penting dilakukan agar dapat menekan side efek hingga seminimal mungkin.

\section{Daftar Pustaka}

Anne, M \& Shelchuk. (2007). Vagal Stimulation for Improving Cardiac Function in Heart Failure or CHF Patients. Dikutip dari http://www.proquest.umi.com

Astiawati T \& Baktijasa, B. (2009). Terapi Nonfarmakologis pada Fibrilasi Atrial. Dikutip dari http://arekkardiounair.blogspot.co $\mathrm{m} / 2009 / 01 /$ terapi-nonfarmakologis-pada-fibrilasi.html

Berek, P. A. L. (2010). Efektifitas Slow Deep Breathing Terhadap Penurunan Tekanan Darah Pada Pasien Hipertensi Primer di Atambua Nusa Tenggara Timur: A Randomized Clinical Trial. Perpustakaan Universitas Indonesia, 1-215. Retrieved from http://lib.ui.ac.id/detail?id=202825 11\&lokasi=lokal\#parentHorizontal Tab2

Berek, P. A. L., Nurachmah, E., \& Gayatri, D. (2015). Effectiveness Of Slow Deep Breathing On Decreasing Blood Pressure In Primary Hypertension : A Randomized Contrrolled Trial Of Patients In Atambua , East Nusa Tenggara. International Journal of Science and Technology, 1(2), 114. Retrieved from http://grdspublishing.org/MATTER /matter.html

Berne, R.M \& Levy, M.N. (1993).

Regulation of Cardiac Contraction. Reprinted from Principles of Physiology $3 \mathrm{rd} \mathrm{Ed}$. Dikutip dari http://www.rfumsphysiology.pb.wi ki.com

Ervin, G. W. (1996). Buku saku perawatan ritis, Ed 2. Alih Bahasa dr. Petrus Andrianto. EGC : Jakarta

Hayashi, I., at all. (2001). Right Vagal Nerve Stimulation for Coronary Anastomosis without Cardiopulmonary Bypass: Investigation in Dogs. Dikutip dari: http://www.proquest.com 
Howland, R. H. (2006). What is Vagus Nerve Stimulation. Dikutip dari http://proquest.umi.com

Klabunde R. E. (2008). Adrenergic and Cholinergic Receptors in the Heart. Retype from Cardiovascular Physiology Concepts. Dikutip dari http://www.cvphysiology.com/Blo od\%20Pressure/BP010.htm

Lewis, M.E., at all. (2001). Vagus Nerve Stimulation Decreases Left Ventricular Contractility In Vivo in the Human and Pig Heart. Dikutip dari http://www.proquest.com

Smeltzer, S. C \& Bare, B. G. (2002). Buku Ajar Keperawatan Medikal Bedah Brunner \& Suddarth. Ed. 8. Vol. 2. EGC : Jakarta
Shelchuk \& Anne, M. (2007). Vagal

Stimulation for Improving Cardiac Function in Heart Failure or CHF Patient. Dikutip dari http://www.google.com

Sparacino, P. S. A., 2005, The clinical nurse specialist. In A. B. Hamric, J. A. Spross \& C. M. Hanson (Eds.), Advanced practice nursing: An integrative approach (3rd ed., pp. 415-446). St. Louis: Elsevier.

Tortora, G. J. \& Derrickson, B. H. (2007). Principles of Anatomy and Physiology. 11th Edition. Dikutip dari http://www.google.com 